\title{
Dynamic viscoelastic properties of experimental silicone soft lining materials
}

\author{
Wallapat SANTAWISUK ${ }^{1}$, Widchaya KANCHANAVASITA², Chakrit SIRISINHA ${ }^{3}$ and Choltacha HARNIRATTISAI ${ }^{4}$ \\ ${ }^{1}$ Department of Conservative Dentistry and Prosthodontics, Faculty of Dentistry, Srinakharinwirot University, Sukhumvit 23 Wattana, Bangkok 10300 , \\ Thailand \\ ${ }^{2}$ Department of Prosthodontics, Faculty of Dentistry, Mahidol University, 6 Yothi Road, Ratchathewee, Bangkok 10400, Thailand \\ ${ }^{3}$ Department of Chemistry, Faculty of Science, Mahidol University, Rama 6 Rd., Bangkok 10400, Thailand \\ ${ }^{4}$ Department of Operative Dentistry, Faculty of Dentistry, Mahidol University, 6 Yothi Road, Ratchathewee, Bangkok 10400, Thailand \\ Corresponding author, Widchaya KANCHANAVASITA; E-mail: dtwkc@mahidol.ac.th
}

\begin{abstract}
The purpose of this study was to evaluate the dynamic viscoelastic properties of experimental silicone soft lining materials, Silastic ${ }^{\circledR}$ MDX 4-4210 reinforced with silica fillers. Storage modulus ( $\left.E^{\prime}\right)$, loss modulus ( $E$ ") and damping factor (tan $\delta$ ) were determined using a dynamic mechanical analyzer under a deformation strain level of $0.27 \%$ at test frequency and a temperature range of $1 \mathrm{~Hz}$ and 0 to $60^{\circ} \mathrm{C}$, respectively. The degree of silica dispersion was also studied using a field emission scanning electron microscopy (FE-SEM). One-way ANOVA and Tukey's HSD test results indicated that the prepared silicone elastomers provided a significantly greater damping factor, but less storage modulus than GC Reline Soft and Tokuyama Sofreliner Tough $(p<0.001)$. The storage moduli, loss moduli and damping factor of the experimental silicone elastomers increased with increasing amounts of fumed silica. In conclusion, the experimental silicone elastomers revealed acceptable dynamic viscoelastic properties to be used as denture soft lining materials.
\end{abstract}

Keywords: Dynamic viscoelastic properties, Silicone elastomer, Soft lining material

\section{INTRODUCTION}

Soft lining materials can be defined as soft, resilient materials forming a cushioned layer between the hard denture base and the oral mucosa. The material absorbs some of the masticatory energy and reduces the energy transmitted to the underlying tissues ${ }^{1}$. It usually acts as a cushion and has the potential of improving comfort of denture wearers. Without a soft liner, the surface hardness of polymethyl methacrylate (PMMA) may lead to chronic soreness ${ }^{2}$.

Silicone elastomers have widely been used as permanent soft lining materials due to their excellent elastic properties; however, they have low cushioning effect, low tear strength and are susceptible to deterioration in the oral environment. Many studies have been conducted to improve the properties of existing silicone materials or to develop new materials for use as permanent denture soft liners ${ }^{3-9)}$.

To enhance the mechanical properties of the silicones, one practical method is an incorporation of hydrophobic surface-treated silica filler with a small particle size and high surface area into silicone matrix. Under deformation, the surface-treated fillers help increase the strength of the elastomer via energy dissipation process by allowing the polymer chains to uncoil and slide past the neighboring chains ${ }^{7}$. Waters et al.5,6) reported that the modified condensation silicones with various hydrophobic silica fillers demonstrated significantly reduced water absorption and the mechanical properties of an experimental silicone mixed with AEROSIL ${ }^{\circledR} \mathrm{R} 812$ were superior to those of Molloplast-B.
In addition to enhancing mechanical properties, viscoelastic properties governing the cushioning effect of soft lining materials, are anticipated to be improved. In the clinical situation, denture soft lining materials are mainly exposed to mechanical forces caused by mastication and swallowing. Dynamic mechanical analysis with the application of cyclic stresses could be utilized to reflect masticatory function, and allows the determination of viscoelastic properties as functions of test temperature and frequency. The storage modulus is closely similar to the elastic contribution of the material. The loss modulus describes the energy dissipation through the viscous response of the material. The damping factor or loss tangent $(\tan \delta)$ is defined as a ratio of storage to loss moduli, which could imply the amount of energy absorbed by the material. It has been reported that silicone materials possess a relatively low damping factor compared with acrylic and fluoroelastomer materials ${ }^{10,11}$. To improve the damping behavior of silicone materials, a limited number of research studies have focused on the use of reinforcing silica filler.

The purpose of this study was to develop a silicone soft lining material with enhanced mechanical and viscoelastic properties by incorporating hydrophobic surface-treated silica filler into Silastic ${ }^{\mathbb{B}}$ MDX4-4210 silicone elastomer (Dow Corning Corp., MI, USA). The dynamic viscoelastic properties of the experimental silicone elastomers were compared with two commercially available silicone soft lining materials. 


\section{MATERIALS AND METHODS}

The materials used in this study are shown in Table 1.

\section{Specimen preparation}

The base part of Silastic ${ }^{\circledR}$ MDX4-4210 silicone elastomer (MDX) was mixed with hydrophobic surfacetreated silica filler, AEROSIL ${ }^{\circledR} \mathrm{R}$ 812S (R 812S), at different loadings $(2,4,6,8$, and 10 parts per hundred parts of rubber (phr)) for 60 minutes as follows:

1. Exp. A contained $2 \mathrm{phr}$ silica filler

2. Exp. B contained $4 \mathrm{phr}$ silica filler

3. Exp. C contained $6 \mathrm{phr}$ silica filler

4. Exp. D contained $8 \mathrm{phr}$ silica filler

5. Exp. E contained $10 \mathrm{phr}$ silica filler

The modified base was then mixed with catalyst according to the manufacturer recommended ratio of 10:1 by weight for 20 minutes using a mixer with mixing speed of $150 \mathrm{rpm}$. A constant vacuum of 0.095 $\mathrm{MPa}$ was applied for 10 minutes to remove air bubbles. The mixture was poured onto a machined stainless steel mold to prepare a rectangular cross section specimen $(10 \times 30 \times 3 \mathrm{~mm})$. A lid was placed on top and a load of $1 \mathrm{~kg}$ was applied to extrude any excessive material. Curing time was 72 hours at room temperature according to manufacturer instructions.

For the commercial materials, GC Reline Soft (RS) and Tokuyama Sofreliner Tough (ST), the base part of each material was mixed with catalyst using the automixer and the mixture was injected onto a machined stainless steel mold. The molding process was the same as that of the experimental silicones.

\section{Dynamic mechanical analysis}

The dynamic mechanical properties of the silicone elastomers were measured using a dynamic mechanical analyzer (Gabo Eplexor ${ }^{\circledR}$ 25N, Ahlden, Germany) as illustrated in Fig. 1 based on a non-resonance-forced vibration principle according to ISO 4664-112).

Five specimens of each group and commercial material were tested under tension mode of deformation. The specimen was gripped longitudinally between two clamps. The temperature sweep test from 0 to $60^{\circ} \mathrm{C}$ was performed to simulate change in viscoelastic response as a function of the service environment of denture soft liners. Also, the strain

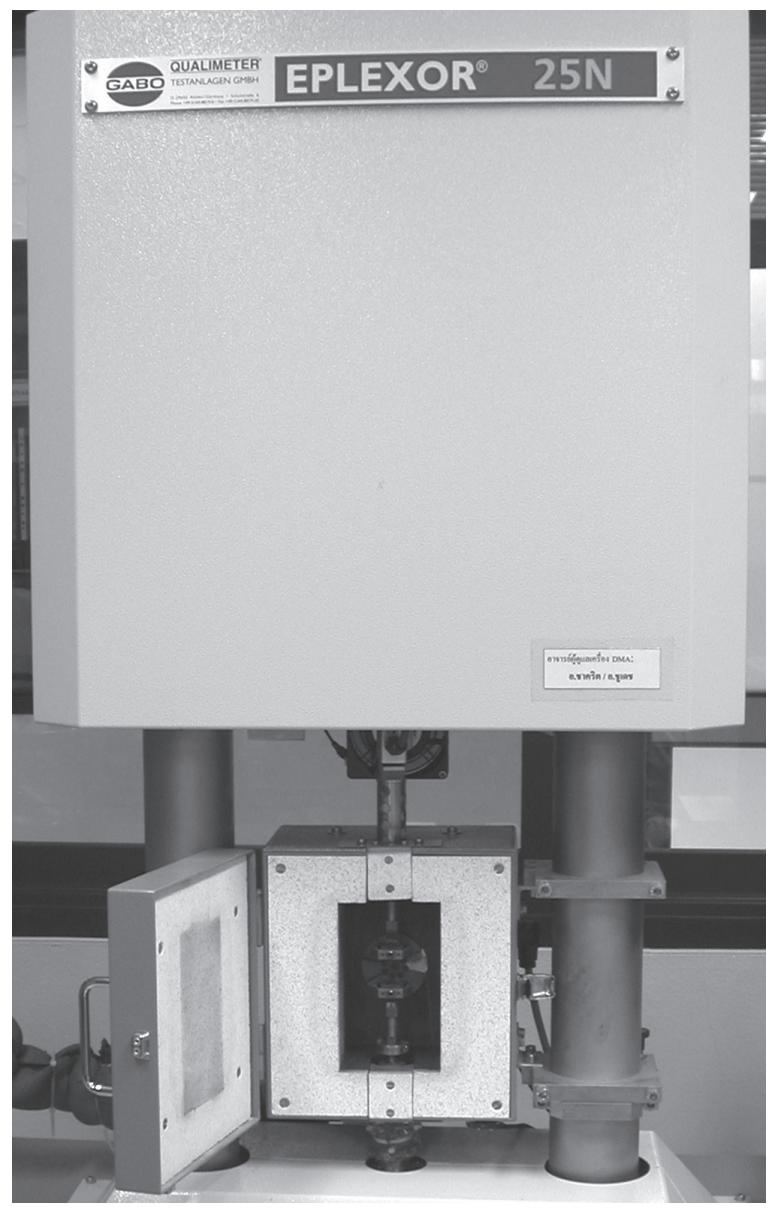

Fig. 1 Dynamic mechanical analyzer

Table 1 Materials used in this study

\begin{tabular}{|c|c|c|c|}
\hline Materials & Description & Manufacturer & Composition \\
\hline $\begin{array}{l}\text { Silastic }^{\circledR} \text { MDX } \\
4-4210 \\
\text { Base \& catalyst } \\
\text { Lot no. } 3438766\end{array}$ & $\begin{array}{l}\text { Addition-cured medical } \\
\text { grade RTV silicone }\end{array}$ & $\begin{array}{l}\text { Dow Corning Corp., } \\
\text { MI, USA }\end{array}$ & $\begin{array}{l}\text { Polydimethyl siloxane } \\
\text { dimethyl vinyl-terminated } \\
\text { with } 15-40 \% \\
\text { trimethylated silica }\end{array}$ \\
\hline $\begin{array}{l}\text { Silica filler } \\
\text { AEROSIL }^{\circledR} \mathrm{R} 812 \mathrm{~S} \\
\text { Lot no. } 3155120635\end{array}$ & $\begin{array}{l}\text { Hydrophobic surface- } \\
\text { treated fumed silica } \\
\text { filler, particle size } 7 \mathrm{~nm}\end{array}$ & $\begin{array}{l}\text { Degussa, Cheshire, } \\
\text { UK }\end{array}$ & $\begin{array}{l}\text { Silicon dioxide } \\
\text { Surface treated with } \\
\text { hexamethyl disilazane }\end{array}$ \\
\hline $\begin{array}{l}\text { Tokuyama } \\
\text { Sofreliner Tough } \\
\text { Lot no. } 046\end{array}$ & $\begin{array}{l}\text { Commercial } \\
\text { RTV silicone soft } \\
\text { lining material }\end{array}$ & $\begin{array}{l}\text { Tokuyama Dental } \\
\text { Corp.,Tokyo, Japan }\end{array}$ & $\begin{array}{l}\text { Polyorganosiloxane with } \\
20 \% \text { amorphous silica }\end{array}$ \\
\hline $\begin{array}{l}\text { GC Reline Soft } \\
\text { Lot no. } 801301\end{array}$ & $\begin{array}{l}\text { Commercial } \\
\text { RTV silicone soft } \\
\text { lining material }\end{array}$ & $\begin{array}{l}\text { GC Dental Products } \\
\text { Corp., Tokyo, Japan }\end{array}$ & $\begin{array}{l}\text { polyvinyl dimethyl siloxane } \\
\text { with } 50-55 \% \text { silica }\end{array}$ \\
\hline
\end{tabular}


sweep test was conducted at a controlled test temperature of $37 \pm 1^{\circ} \mathrm{C}$. Results of storage moduli, loss moduli and damping factor of the materials at strain and frequency of $0.27 \%$ and $1 \mathrm{~Hz}$ were compared.

It is known that the storage modulus ( $\left.E^{\prime}\right)$ describes elasticity of materials while the loss modulus ( $E$ ") represents viscous response. The damping factor or loss tangent $(\tan \delta)$ as a ratio of the loss modulus and the storage modulus $\left(E^{\prime \prime} / E^{\prime}\right)$ are considered as an indication of the cushioning effect of the denture soft liners.

\section{Scanning electron microscopy}

The state-of-mix or degree of silica dispersion in the silicone elastomers was monitored using a field emission SEM (FE-SEM: JSM-6340F, JEOL, Tokyo, Japan). The sample preparation was achieved by cryogenic fracturing a thin cross-section of test specimen, and then mounting on sample holders. The specimen was sputter-coated with gold and the crosssectional area was then observed at 20,000×magnification.

\section{Statistical analysis}

All statistical analyses were performed using SPSS software package (Statistical Package for Social Sciences, version 16.0, SPSS Inc, Chicago, IL, USA). The Kolmogorov-Smirnov test was used to determine the normal distribution of collected data, and the Levene statistics was used to determine the homogeneity of variances. Differences between the test groups for each property were found using one way analysis of variance and Tukey's HSD test $(\alpha=0.05)$.

\section{RESULTS}

Results of viscoelastic properties are given in Figs. 2 and 3. Storage moduli, loss moduli and damping factor of the experimental silicone elastomers were found to increase with increasing silica loading.

Storage modulus of Exp. E (2.21 MPa) was significantly higher than other experimental groups $(p<0.001)$. RS exhibited the highest storage modulus (4.45 MPa), significantly greater than that of ST (3.12 MPa) $(p<0.001)$. Unfilled MDX revealed the lowest storage modulus (1.03 $\mathrm{MPa})$.

Loss modulus of Exp. E was the highest (0.206 $\mathrm{MPa})$, significantly higher than other groups $(p<0.001)$. RS had a significantly higher loss modulus (0.187 MPa) than that of ST $(0.093 \mathrm{MPa})(p<0.001)$. No statistically significant differences were found between Exp. B (0.099 MPa) and ST $(p=0.176)$. MDX had the lowest loss modulus (0.061 MPa).

Evidently, all silicone elastomers prepared exhibited significantly greater damping factor than both commercial soft lining materials $(p<0.001)$. ST had the lowest damping factor (0.03).

In addition, to observe damping behavior as a function of the service temperature range of $0-60^{\circ} \mathrm{C}$, the temperature sweep test was conducted, and the results obtained are illustrated in Fig. 4. Evidently, the result trends of damping factor at any given test temperature were similar in a way that the silicone elastomers prepared in the present study still exhibited greater damping factor than both commercial silicone materials regardless of the service temperature in a range of $0-60^{\circ} \mathrm{C}$.

The dispersion of silica in the silicone elastomers as determined from FE-SEM is shown in Fig. 5. In the sample of MDX, no silica aggregates were detected. As the silica loading was increased (from 2 phr to $10 \mathrm{phr}$ ), the magnitude of silica aggregation in the silicone matrix was observed. Agglomeration of silica particles were noticed in some areas of the specimen with high silica loading of $10 \mathrm{phr}$.

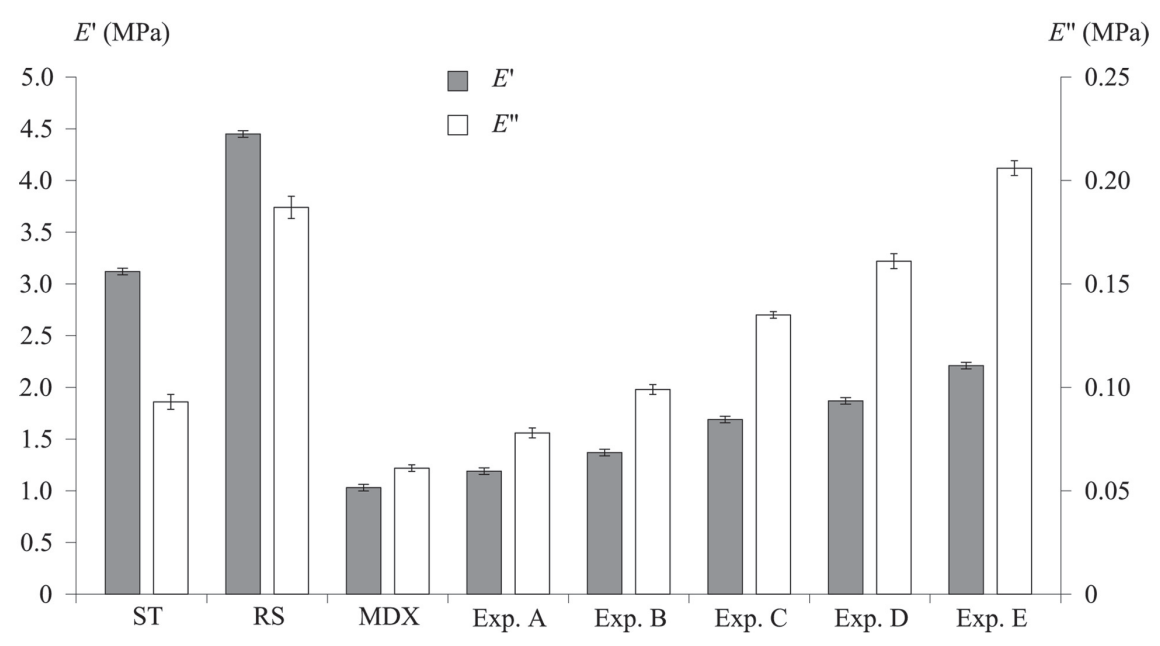

Fig. 2 Mean values and standard deviations of storage modulus (E': primary Y-axis) and loss modulus (E": secondary Y-axis) of Tokuyama Sofreliner Tough (ST), GC Reline Soft (RS), Silastic ${ }^{\circledR}$ MDX4-4210 (MDX), and experimental silicone elastomers (Exp. A-E) 


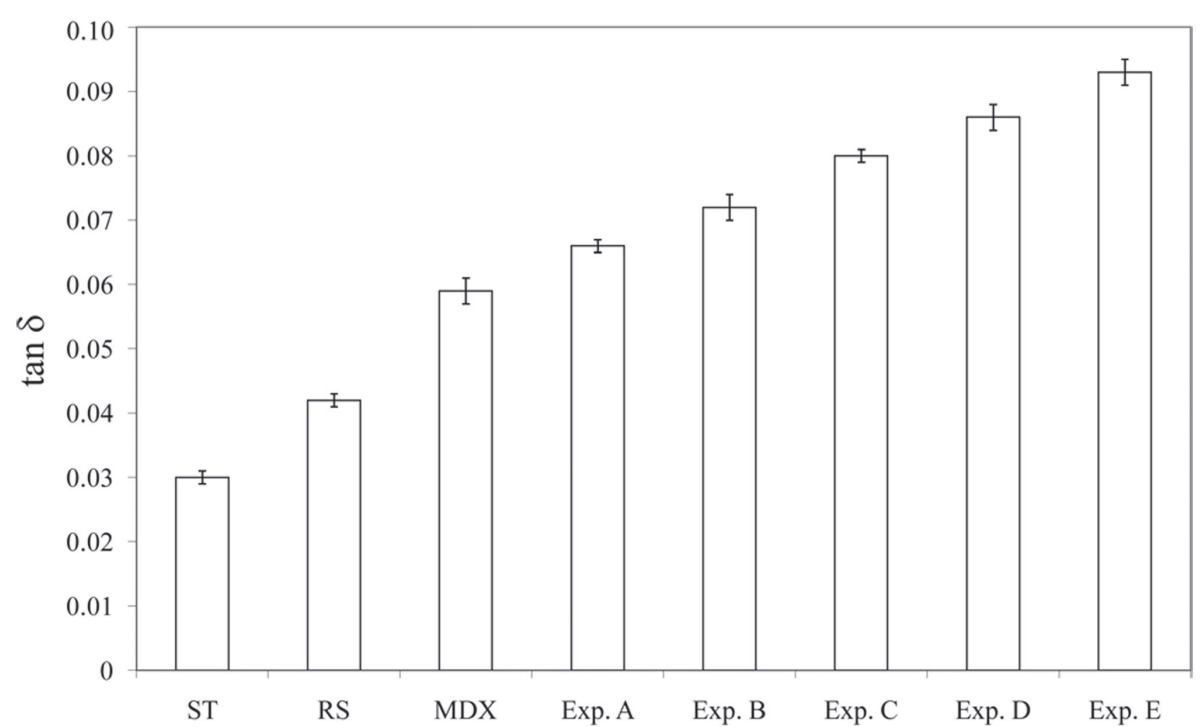

Fig. 3 Mean values and standard deviations of damping factor (tan $\delta$ ) of Tokuyama Sofreliner Tough (ST), GC Reline Soft (RS), Silastic ${ }^{\circledR}$ MDX4-4210 (MDX), and experimental silicone elastomers (Exp. A-E)

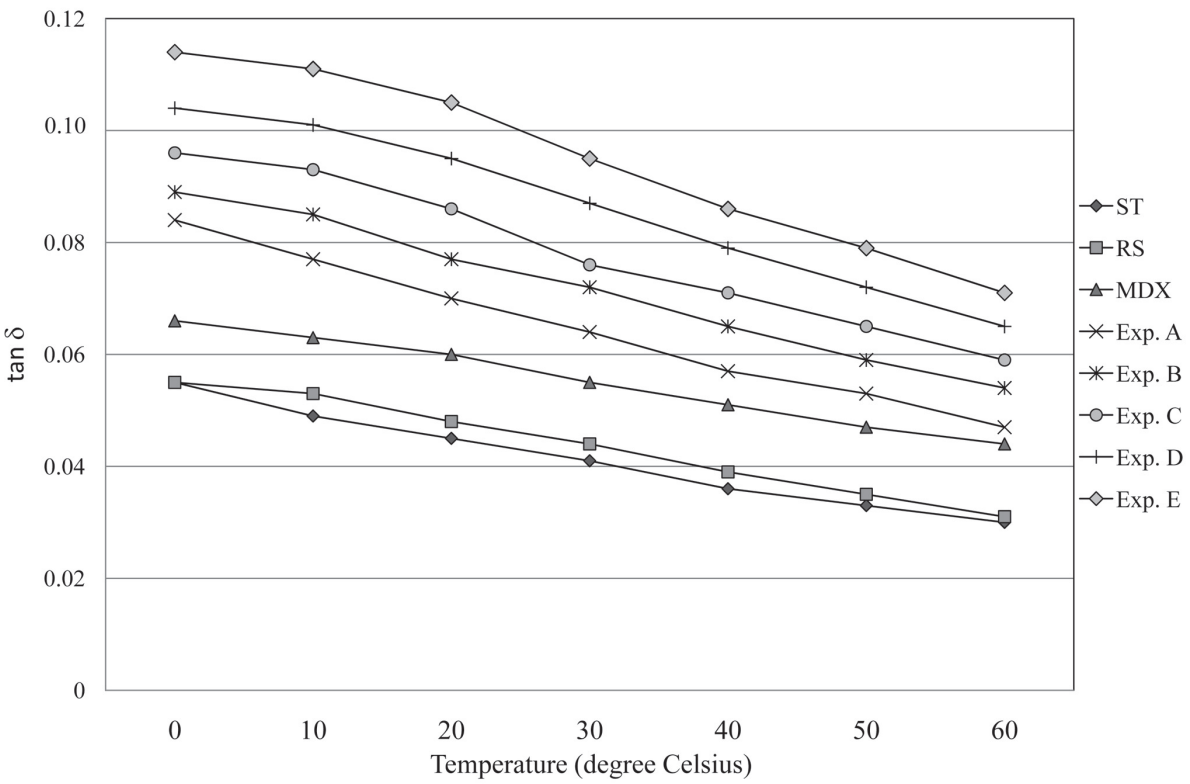

Fig. 4 Damping factor $(\tan \delta)$ as a function of temperature of Tokuyama Sofreliner Tough (ST), GC Reline Soft (RS), Silastic ${ }^{\circledR}$ MDX4-4210 (MDX), and experimental silicone elastomers (Exp. A-E)

\section{DISCUSSION}

The ideal soft lining material should be soft to dissipate the applied stresses, and provide patient compliance with acceptable mechanical properties. Additionally, long-term soft lining materials should possess a sufficient magnitude of cushioning effect (i.e., damping factor) to absorb functional stress via the energy dissipation process with minimal permanent set over time. Silicone elastomer is widely used as a long-term soft lining material because of its good viscoelastic properties and durability. However, commercial silicone soft lining materials still exhibit unfavorable mechanical properties and exhibit clinical deficiencies such as low damping factor, poor tear strength and 

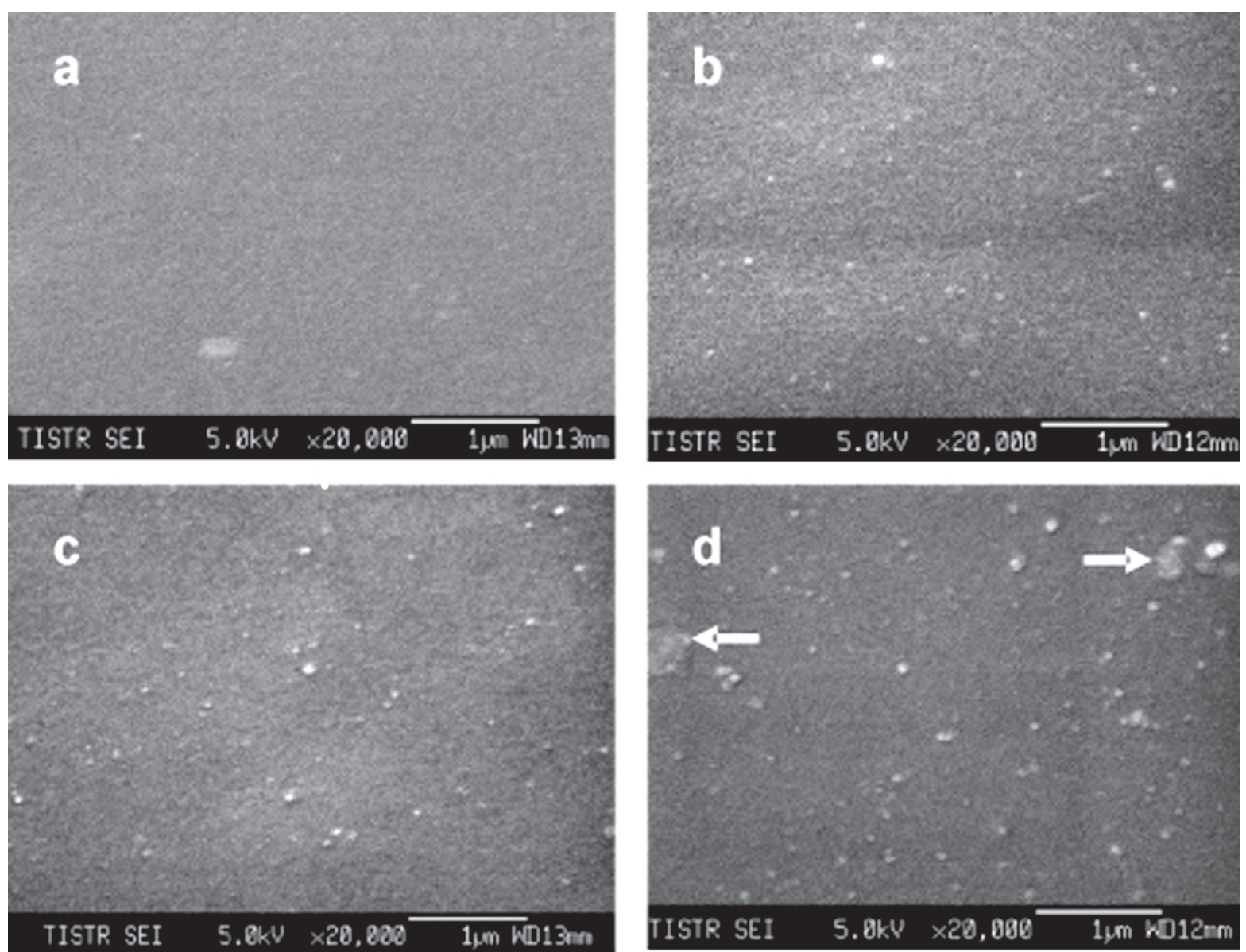

Fig. 5 FE-SEM images (20,000×) of a. Silastic ${ }^{\circledR}$ MDX4-4210 (MDX), b. the experimental silicone elastomer with $2 \mathrm{phr}$ silica loading (Exp. A), c. the experimental silicone elastomer with $6 \mathrm{phr}$ silica loading (Exp. C), and d. the experimental silicone elastomer with $10 \mathrm{phr}$ silica loading (Exp. E). Agglomeration of silica particles were observed (arrows).

high surface hardness ${ }^{7,11}$.

Silastic $^{\circledR}$ MDX4-4210, a medical grade room temperature-vulcanizing (RTV) silicone elastomer, is widely used to fabricate maxillofacial prostheses ${ }^{13,14)}$ due to its improved mechanical properties, combining the advantage of both high temperature-vulcanizing (HTV) and RTV addition-cured silicone. Therefore, MDX has the potential to be used as a soft lining material.

In this study, hydrophobic surface-treated fumed silica filler was used to reinforce MDX silicone elastomer. Fumed silica with high surface area is used to maximize the polymer/filler interactions, leading to high reinforcement magnitude and thus mechanical strength. AEROSIL ${ }^{\circledR} \mathrm{R} 812 \mathrm{~S}$ is a hydrophobic surfacetreated fumed silica with average particle size and a BET surface area of $7 \mathrm{~nm}$ and $220 \pm 25 \mathrm{~m}^{2} / \mathrm{g}$, respectively ${ }^{7}$. The hexamethyl disilazane surfacetreated groups on these silica surfaces could repel water molecules and hence prevent water absorption into the cured material ${ }^{5}$. The silane surface treatment of the fumed silica could enhance elastomer-silica interaction via covalent bonds. By this means, the resulting elastomeric matrix is able to withstand greater deformation without rupture or tearing ${ }^{15)}$.

Apart from the increase in filler-rubber interaction, the silane treatment could improve the dispersion of fumed silica by a reduction in silica agglomeration via H-bond, which could be supported by the SEM images as shown in Fig. 5. It is evident that the magnitude of silica aggregation increases with increasing silica loading. Compared with silicone having $2 \mathrm{phr}$ silica loading (Exp. A), the sample filled with $10 \mathrm{phr}$ silica loading (Exp. E) revealed a high magnitude of silica agglomerates. In other words, the increase in loading of fumed silica would result in a difficulty in the mixing process.

As for the viscoelastic response of silicone prepared with different fumed silica loading, it is evident that elastic moduli, loss moduli and especially damping factor were promoted. Typically, dynamic mechanical analysis $^{11,16)}$ is used to characterize a wide range of polymeric materials permitting the determination of three crucial parameters of polymeric materials, 
namely, storage modulus ( $\left.E^{\prime}\right)$; loss modulus (E"); and phase angle $(\delta)$. By definition, the loss modulus, $E$ ", defines dissipation of energy within a material, and damping factor or loss tangent $(\tan \delta$ ) indicates the ability of a material to dissipate mechanical energy through conversion into heat by molecular motion. Damping factor is calculated from the ratio of the loss modulus to the storage modulus ( $\left.\tan \delta=E^{\prime \prime} / E^{\prime}\right)$, and usually used as an index of material viscoelasticity. In the present study, the test frequency of $1 \mathrm{~Hz}$ was considered to be important to assess clinical significance in terms of the masticatory rhythm while the test temperature of $37 \pm 1^{\circ} \mathrm{C}$ could represent the service environment of the soft lining material ${ }^{10,11,17)}$. The deformation strain of $0.27 \%$ reported in this study was in the linear viscoelastic (LVE) region, and was also used in the previous study of Murata et al. ${ }^{11}$. However, one might be interested in damping behavior as a function of broad service temperature range apart from $37^{\circ} \mathrm{C}$. Thus, the temperature sweep test was performed, and the results gained are exhibited in Fig. 4. Clearly all specimens showed decreases in damping factor as any given temperature, which is not surprising because such decreases are due mainly to the increase in molecular free volume facilitating the elastic response. The interesting point is the result trends are in a similar manner that the damping factor increases with increasing silica loading regardless of the test temperature. Thus, in this study, the viscoelastic properties at $37^{\circ} \mathrm{C}$ are discussed.

From the results as shown in Figs. 2 and 3, both commercial silicone soft lining materials had significantly greater storage modulus but less damping factor than the experimental silicone elastomers and MDX. The results agree with the studies of Wagner et $a l .{ }^{10)}$ and Murata et $a l .{ }^{11)}$ in a way that that the silicones exhibited low damping factor $(0.02-0.05)$. The experimental silicone elastomer with $10 \mathrm{phr}$ silica loading (Exp. E) was found to possess remarkably high loss modulus. Only the RS had greater loss modulus than the experimental silicones with silica loadings lower than $10 \mathrm{phr}$. No statistically significant differences were found between the loss moduli of Exp. B (silica loading of $4 \mathrm{phr}$ ) and ST. The silicone elastomers prepared in this study exhibited higher magnitude of energy dissipation via hysteretic behavior while ST and RS exhibited more elastic response.

Damping efficiency as indicated by a value of $\tan \delta$ is one of the considerably important properties of soft lining materials. Materials should theoretically possess a high magnitude of energy dissipation, which would reduce the transmission of mechanical stresses directly to the denture-bearing tissues. By this means, the masticatory pain could be prevented effectively. Unfortunately, the damping factor of commercial silicones was found to be very low, approaching zero, limiting the cushioning effect required for ideal permanent soft lining materials. Apparently, the silicone elastomers developed in this study could provide greater magnitude of damping efficiency, depending on silica loading.

In the case of silica-filled elastomers, the formation of transient pseudo-network was possible via the strong silica-silica particles due to the presence of the silanol group on silica surfaces. However, at high strain of deformation, such transient network could be disrupted leading to an increase in damping factor. In other words, the cyclic disruption and reformation of the transient network could affect the viscoelasticity of silica-filled elastomers to some extent. The interactions between the original filler and the hydrophobic surfacetreated fumed silica, R 812S, are still questionable at present. It is proposed that the hydrophobic portion of silane on original silica surfaces would interact with that on $\mathrm{R} 812 \mathrm{~S}$ surfaces via Van der Waals force ${ }^{5}$. Additionally, the incomplete silane treated surfaces of original and $\mathrm{R} 812 \mathrm{~S}$ fumed silica would lead to the presence of free silanol groups on their surfaces which would interact to each other by hydrogen bonds.

The silicone elastomers developed in this study had significantly greater $\tan \delta$ than both commercial silicone soft lining materials by an incorporation of fumed silica into silicone matrix. In addition, the experimental silicone elastomers with silica loadings of 6,8 , and $10 \mathrm{phr}$ gave higher loss moduli than ST. This high loss modulus could increase the damping efficiency to absorb mechanical stress caused by masticatory process. In other words, the experimental silicone elastomers showed a good potential to be used as soft lining materials. However, not only the damping factor is required for the ideal soft lining materials, but also the durability is important for long-term use. This study is a preliminary study and the investigation of long-term viscoelastic and mechanical properties of the experimental silicone soft lining materials is still in process of further studies.

\section{CONCLUSIONS}

1. The modification of Silastic ${ }^{\circledR}$ MDX4-4210 silicone elastomer with hydrophobic surface-treated fumed silica, AEROSIL ${ }^{\circledR} \mathrm{R}$ 812S, could improve damping behavior remarkably with significantly greater damping factor than two commercial silicone soft lining materials.

2. The storage moduli, loss moduli and damping factor of the experimental silicone elastomers increased with increasing amounts of fumed silica.

3. The experimental silicone elastomers in the present study were found to have acceptable viscoelastic properties to be used as denture soft lining materials. However, the viscoelastic properties should be evaluated long term as an implication of material durability.

\section{ACKNOWLEDGMENTS}

This study based on a thesis submitted to the Faculty of Graduate Studies, Mahidol University, Thailand. 


\section{REFERENCES}

1) McCabe JF, Carrick TE, Kamohara H. Adhesive bond strength and compliance for denture soft lining materials. Biomaterials 2002; 23: 1347-1352.

2) Storer R. Resilient denture base materials. Br Dent J 1962; 113: 95.

3) Moore DJ, Glazer ZR, Tobacco MJ, Linebaugh MG. Evaluation of polymeric materials for maxillofacial prosthetics. J Prosthet Dent 1977; 38: 319-324.

4) Farah JW, Robinson JC, Koran A, Craig RG, Hood JAA. Properties of a modified cross-linked silicone for maxillofacial prostheses. J Oral Rehabil 1987; 14: 599-605.

5) Waters MGJ, Jagger RG, Winter RW. Effect of surface modified fillers on the water absorption of a (RTV) silicone denture soft lining material. J Dent 1996; 24: 297-300.

6) Waters MGJ, Jagger RG. Mechanical properties of an experimental denture soft lining material. J Dent 1999; 27: 197-202.

7) Aziz T, Waters M, Jagger R. Development of a new poly(dimethylsiloxane) maxillofacial prosthetic material. J Biomed Mater Res B 2003; 65: 252-261.

8) Gunay Y, Kurtoglu C, Atay A, Karayazgan B, Gurbuz CC. Effect of tulle on the mechanical properties of a maxillofacial silicone elastomer. Dent Mater J 2008; 27: 775-779.

9) Kanie T, Tomita K, Tokuda M, Arikawa H, Fujii K, Ban S.
Mechanical properties and cytotoxicity of experimental soft lining materials based on urethane acrylate oligomers. Dent Mater J 2009; 28: 501-506.

10) Wagner WC, Kawano F, Dootz ER, Koran III A. Dynamic viscoelastic properties of processed soft denture liners: Part I-Initial properties. J Prosthet Dent 1995; 73: 471-477.

11) Murata H, Taguchi N, Hamada T, McCabe JF. Dynamic viscoelastic properties and the age changes of long-term soft denture liners. Biomaterials 2000; 21: 1421-1427.

12) International Organization for Standardization ISO 4664-1: Rubber, vulcanized or thermoplastic - Determination of dynamic properties Part 1: General Guidance. 1st ed. Geneva, 2005.

13) Beumer J, Curtis TA, Marunick MT. Maxillofacial rehabilitation: Prosthodontic and surgical considerations. St. Louis: Ishiyaku Euro America Inc; 1996. p. 387-399.

14) Andres CJ, Haug SP, Brown DT, Bernal G. Effects of environmental factors on maxillofacial elastomers: Part IIReport of survey. J Prosthet Dent 1992; 68: 519-522.

15) Aziz T, Waters M, Jagger R. Analysis of the properties of silicone rubber maxillofacial prosthetic materials. J Dent 2003; 31: 67-74.

16) Braden M, Clarke RL. Visco-elastic properties of soft lining materials. J Dent Res 1972; 51: 1525-1528.

17) Murata H, Taguchi N, Hamada T, Kawamura M, McCabe JF. Dynamic viscoelasticity of soft liners and masticatory function. J Dent Res 2002; 81: 123-128. 